\title{
Synapse-Glia Interactions at the Mammalian Neuromuscular Junction
}

\author{
Danielle Rochon, Isabelle Rousse, and Richard Robitaille \\ Centre de Recherche en Sciences Neurologiques and Département de Physiologie, Université de Montréal, Montréal, \\ Quebec, Canada H3C 3J7
}

Perisynaptic Schwann cells (PSCs) play critical roles in regulating and stabilizing nerve terminals at the mammalian neuromuscular junction (NMJ). Howe1er, although these functions are likely regulated by the synaptic properties, the interactions of PSCs with the synaptic elements are not known. Therefore, our goal was to study the interactions between mammalian PSCs in situ and the presynaptic terminals using changes in intracellular $\mathrm{Ca}^{2+}$ as an indicator of cell activity. Motor nerve stimulation induced an increase in intracellular $\mathrm{Ca}^{2+}$ in PSCs, and this increase ÿas greatly reduced when transmitter release was blocked. Furthermore, local application of acetylcholine induced $\mathrm{Ca}^{2+}$ responses that were blocked by the muscarinic antagonist atropine and mimicked by the muscarinic agonist muscarine. The nicotinic antagonist $\alpha$-bungarotoxin had no effect on $\mathrm{Ca}^{2+}$ responses induced by acetylcholine. Local application of the cotransmitter ATP induced $\mathrm{Ca}^{2+}$ responses that were unaf-

Recent evidence indicates that there are dynamic, bidirectional interactions between glial cells and neurons. Indeed, not only are glial cells modulated by nerve-evoked transmitter release but they, in turn, modulate neuronal activity (Nedergaard, 1994; Parpura et al., 1994; Pfrieger and Barres, 1997; Bezzi et al., 1998; Newman and Zahs, 1998; Robitaille, 1998).

The vertebrate neuromuscular junction (NMJ) is an interesting preparation to study synapse-glia interactions because it is a simple synapse where the anatomical relationship between presynaptic, postsynaptic, and glial elements is maintained. Perisynaptic Schwann cells (PSCs) or terminal Schwann cells, glial cells at this synapse, have been studied at the amphibian NMJ and have been shown to detect synaptic activity, as revealed by an elevation in intracellular calcium (Jahromi et al., 1992; Robitaille, 1995). PSCs possess purinergic and muscarinic receptors as well as neurokinin-1 (NK-1) receptors for substance P (Robitaille, 1995; Robitaille et al., 1997; Bourque and Robitaille, 1998), and their activity is governed by these receptors (Georgiou et al., 1994, 1999; Bourque and Robitaille, 1998). Moreover, as a consequence of synaptic activity, PSCs modulate the efficacy of the

\footnotetext{
Received Nov. 2, 2000; revised March 16, 2001; accepted March 19, 2001.

This work was supported by Grant MT14137 from the Canadian Institute of Health Research (CIHR), by awards from the EJLB Research Foundation and The Alfred P. Sloan Foundation, and by a team grant from Fonds pour la Formation de Chercheurs et de l'aide à la Recherche to R.R. I.R. was sponsored by a studentship from Schering, and R.R. was a Junior II Scholar from the Fonds de la Recherche en Santé du Québec and a CIHR Investigator. We thank Rhoda L. Kenigsberg and Vincent F. Castellucci for their comments and suggestions on this manuscript.

Correspondence should be addressed to Richard Robitaille, Département de physiologie, Université de Montréal, P. O. Box 6128, Station "Centre-Ville", Montréal, Quebec, Canada H3C 3J7. E-mail: richard.robitaille@umontreal.ca. Copyright (C) 2001 Society for Neuroscience $0270-6474 / 01 / 213819-11 \$ 15.00 / 0$
}

fected by the P2 antagonist suramin, whereas local application of adenosine induced $\mathrm{Ca}^{2+}$ responses that were greatly reduced by the A1 receptor antagonist 8-cyclopentyl-1,3-dimethylxanthine (CPT). However, the presence of the A1 antagonist in the perfusate did not block responses induced by ATP. $\mathrm{Ca}^{2+}$ responses evoked by stimulation of the motor nerve were reduced in the presence of CPT, whereas atropine almost completely abolished them. $\mathrm{Ca}^{2+}$ responses were further reduced when both antagonists were present simultaneously. Hence, PSCs at the mammalian NMJ respond to the release of neurotransmitter induced by stimulation of the motor nerve through the activation of muscarinic and adenosine $\mathrm{A} 1$ receptors.

Key words: adenosine; acetylcholine; $\mathrm{Ca}^{2+}$, perisynaptic Schwann cell; transmitter release; neuromuscular junction; synapse-glia interactions

synapse by regulating transmitter release (Robitaille, 1998; Castonguay and Robitaille, 2001).

PSCs also modulate nerve growth and synapse maintenance. Although recent evidence has been obtained at the amphibian NMJ (Herrera et al., 2000; Koirala et al., 2000), most evidence has been obtained at the mammalian NMJ. For instance, processes extended by PSCs after denervation influence the regrowth of motor axons to the muscles and their guidance back to denervated NMJs (Son et al., 1996). Furthermore, immunocytochemical markers specific for Schwann cells, synapses, and motor axons were used to show that motor axons navigate along the processes extended by PSCs from the damaged nerve endings (Son and Thompson, 1995a,b). The guidance of axons by PSCs lead to clustering of motor units, a phenomenon typical of many neurogenic pathologies (Son et al., 1996). Notwithstanding the functional importance of PSCs, very little is known about their properties at the mammalian NMJ where, in fact, no evidence of direct modulation of synaptic activity is available andä where the properties are not characterized. Moreover, although synapseglia interactions appear to be a common phenomenon at chemical synapses (Araque et al., 1999; Castonguay et al., 2001), it is still unclear how much the properties of these interactions differ between related synapses. Hence, this study aimed to characterize PSCs properties at the mammalian NMJ to determine functional similarities and differences with the properties of the amphibian NMJ.

We report that, similar to PSCs at amphibian NMJ, PSCs at the mammalian NMJ respond to the release of neurotransmitters induced by stimulation of the motor nerve via activation of muscarinic receptors. However, the role of the purinergic recep- 
tors of PSCs at the mammalian NMJ differs where A1 adenosine receptors, but not $\mathrm{P} 2$ receptors, contribute to the activation of PSCs. Hence, these results indicate that although synapse-glia interactions are present at chemical synapses in situ, these interactions are governed by specialized features related to the synapse with which glial cells are associated.

\section{MATERIALS AND METHODS}

Nerve-muscle preparation. Experiments were performed at room temperature on levator auris longus nerve-muscle preparations dissected from CD1 mice (22-24 gm; Charles River Laboratories, Wilmington, MA). Muscles were removed under deep anesthesia (midazolam and hypnorm dissolved in water). The normal Ringer's solution contained (in mM): 124 $\mathrm{NaCl}, 5 \mathrm{KCl}, 1.25 \mathrm{NaH}_{2} \mathrm{PO}_{4} 2 \mathrm{MgCl}_{2}, 2 \mathrm{CaCl}_{2}, 26 \mathrm{NaHCO}_{3}$, and 10 glucose. A $0 \mathrm{Ca}^{2+} / 5 \mathrm{mM} \mathrm{Mg}^{2+}$ physiological solution contained (in $\mathrm{mM}$ ): $124 \mathrm{NaCl}, 5 \mathrm{KCl}, 1.25 \mathrm{NaH}_{2} \mathrm{PO}_{4}, 5 \mathrm{MgCl}_{2}, 26 \mathrm{NaHCO}_{3}$, and 10 glucose. Solutions were oxygenated with a gas mixture of $95 \% \mathrm{O}_{2}$ and $5 \% \mathrm{CO}_{2}$.

Calcium imaging of mammalian PSCs. Muscles were incubated for $90 \mathrm{~min}$ at room temperature in a physiological solution saturated with $95 \% \mathrm{O}_{2}$ and $5 \% \mathrm{CO}_{2}$ and containing $20 \mu \mathrm{M}$ fluo-3 AM (Molecular Probes, Eugene, OR; Tsien, 1989), $0.02 \%$ pluronic acid (Molecular Probes), and $0.5 \%$ dimethylsulfoxide (Sigma, St. Louis, MO). Muscles were then pinned down in a recording chamber coated with Sylgard. Partial chelation of heavy metal ions was achieved using $20 \mu \mathrm{M}$ tetrakis (2-pyridylmethyl) ethylenediamine (Molecular Probes) to limit binding of these ions to fluo-3. Changes in fluorescence intensity were monitored using a Bio-Rad (Hercules, CA) 600 laser-scanning confocal microscope equipped with an argon ion laser. The $488 \mathrm{~nm}$ laser line was attenuated to $1 \%$ intensity, and a long-pass filter with cutoff at $515 \mathrm{~nm}$ was used to detect the emitted fluorescence. A $40 \times$ water immersion lens was used (0.75 NA; Olympus, Tokyo, Japan). Surface NMJs were located using transmitted light microscopy. The intensity of fluorescence $(F)$ was measured over the area of the PSCs cell body, and the relative changes in fluorescence intensity were expressed as $\% \Delta F / F=(F-$ $\left.F_{\text {rest }}\right) / F_{\text {rest }} \times 100$.

Drug applications. ATP, adenosine, muscarine, and acetylcholine (20 $\mu \mathrm{M})$ were dissolved in the same saline as that in the recording chamber. Drugs were applied directly by micropressure (5-10 PSI; pulse duration, $200 \mathrm{msec}$ ) to selected cells with a micropipette (tip diameter, 2-4 $\mu \mathrm{M}$ ) using a Picospritzer II (General Valve, Fairfield, NJ). The local application of the agonists induced a slight movement of the muscle fiber that moved briefly out of focus resulting in a small deflection in the fluorescence level (see Figs. 3-7). The micropipette was positioned near the PSC somata under visual control at high magnification $(40 \times$ water immersion objective). There was no increase in fluorescence when Ringer's solution was applied alone. When several applications were performed on the same cells, a recovery period of at least $15 \mathrm{~min}$ was allowed between each application. For the $\mathrm{Ca}^{2+}$-free $/ 5 \mathrm{mM} \mathrm{Mg}^{2+}$ experiments, preparations were perfused in the modified physiological solution for 25-30 min before the experiments. Some antagonists ( $\alpha$-bungarotoxin, $\omega$-conotoxin MVIIC) were applied directly in the recording chamber in a closed bath, whereas suramin, 8-cyclopentyl-1,3-dimethylxanthine (CPT), and atropin were applied by bath perfusion.

Stimulation of the motor nerve. Nerve-muscle preparations were processed for fluo-3 AM loading as described above. Stimulation of the distal end of the cut motor nerve $(50 \mathrm{~Hz}, 30 \mathrm{sec})$ was achieved using a suction electrode. To prevent muscle contractions evoked by transmitter release, cholinergic receptors were blocked with $\alpha$-bungarotoxin $(\alpha$ BuTx; $20 \mu \mathrm{M}$; Molecular Probes). Preparations were allowed to rest for 20-25 min between trains of stimuli when several trains were performed on the same preparation.

Immunocytochemistry. After some experiments, muscles were fixed using $4 \%$ paraformaldehyde for $10 \mathrm{~min}$ and rinsed for at least $30 \mathrm{~min}$ in three changes of Ringer's solution. Muscles were then permeabilized in $-20^{\circ} \mathrm{C}$ methanol for $6 \mathrm{~min}$, washed again in Ringer's solution for $30 \mathrm{~min}$, and nonspecific staining was blocked using Ringer's solution's containing $0.3 \%$ Triton X-100 and $0.2 \%$ dry milk. Muscles were incubated overnight at room temperature with a rabbit antibody solution raised against cow S-100 (Dako, Carpinteria, CA) prepared in the solution indicated above (dilution 1:400). After incubation in the primary antibody, muscles were rinsed in three changes of Ringer's solution for $30 \mathrm{~min}$ and incubated in secondary antibody for $1 \mathrm{hr}$ at room temperature. The secondary antibody was an anti-rabbit conjugated to biotin-SP (Jackson ImmunoResearch, West Grove, PA: 1:500) and revealed using avidin FITC (1:100; for $2 \mathrm{hr}$ ). Finally, muscles were rinsed for $10-15 \mathrm{~min}$ in Slowfade antifade reagent (Molecular Probes). Preparations were mounted onto glass slides in Slowfade antifade under a coverslip. Images of the same NMJs studied for $\mathrm{Ca}^{2+}$ imaging were collected under immersion oil with a $40 \times$ lens (Nikon), using the Bio-Rad 600 confocal microscope.

Statistics. Results are presented as mean \pm SEM. A Student paired $t$ test was used when a treatment was performed on the same cell (control vs drug), and an ANOVA was used for comparison between different groups. Both tests were used at a confidence level of $95 \%(\alpha=0.05)$.

\section{RESULTS}

\section{Identification of PSCs at the mammalian NMJ}

The validity of the study of synapse-glia interactions at the mammalian NMJ relies on our ability to identify PSCs. However, unlike PSCs at the frog NMJ, mammalian PSCs are not so easily recognized in bright-field illumination. Mammalian NMJs have an oval shape and are more compact than amphibian NMJs. They terminate in a slight elevation of the muscle fiber, just after the myelin sheath where the nerve terminal forms a compact junction (Salpeter, 1987). The identification of PSCs was achieved based on these characteristics.

We first confirmed that these criteria of identification were reliable by labeling PSCs using an antibody against the calciumbinding protein S-100, which is used as a general marker for Schwann cells (Son and Thompson, 1995a). First, cells were identified by transmitted light according to the criteria indicated above, and preparations were loaded with the permeant fluorescent $\mathrm{Ca}^{2+}$ indicator fluo-3 AM (Fig. $1 A$ ). A brief local application of muscarine increased $\mathrm{Ca}^{2+}$ fluorescence in the cell body of the presumed PSCs (Fig. $1 B$ ) that subsequently decreased back to baseline (see also Figs. 3 and 4). The nerve-muscle preparation was then processed for immunohistochemistry, and the presence of S-100 was revealed. The same NMJ was then found, and an image of S-100 labeling was taken using the confocal microscope. As shown in Figure $1 C$, the same cells identified as PSCs corresponding to our criteria and that showed a $\mathrm{Ca}^{2+}$ response induced by muscarine were also labeled by $\mathrm{S}-100$. These results indicate that they were Schwann cells at the NMJ, and hence, that the criteria used to identify PSCs were appropriate. Also, the myelinating Schwann cells that were also loaded with fluo-3 were also labeled by S-100 (data not shown).

\section{Nerve-evoked $\mathrm{Ca}^{2+}$ responses in perisynaptic Schwann cells}

The sensitivity of mouse PSCs to synaptic transmission and transmitter release was established by monitoring changes in intracellular $\mathrm{Ca}^{2+}$ during synaptic activity induced by repetitive stimulation of the motor nerve. As shown in Figure $2 A$, a train of stimuli $(50 \mathrm{~Hz}, 30 \mathrm{sec})$ triggered an increase in fluorescence. This was observed in all PSCs tested $(n=10)$ with a mean of $157 \pm$ $15 \% \Delta F / F$. This elevation in intracellular $\mathrm{Ca}^{2+}$ occurred, on average, with a delay to onset of $1.5 \mathrm{sec}$ after the beginning of the stimulation, and the time to reach the maximum amplitude was $15 \pm 2 \mathrm{sec} . \mathrm{Ca}^{2+}$ responses decayed to baseline in $82.2 \pm 12 \mathrm{sec}$, which occurred well after the interruption of nerve stimulation. In addition, in all PSCs studied, the initial $\mathrm{Ca}^{2+}$ response was always followed by a second smaller elevation that occurred after a partial recovery of the initial response. Nerve stimulation at lower frequencies $(10,15$, or $25 \mathrm{~Hz})$ resulted in smaller $\mathrm{Ca}^{2+}$ responses than the ones obtained with stimulation at $50 \mathrm{~Hz}$ (data not shown). As seen in Figure $2 A$, a second train of stimuli given 20 min after the first one (break in the $x$-axis) hardly elicited a 

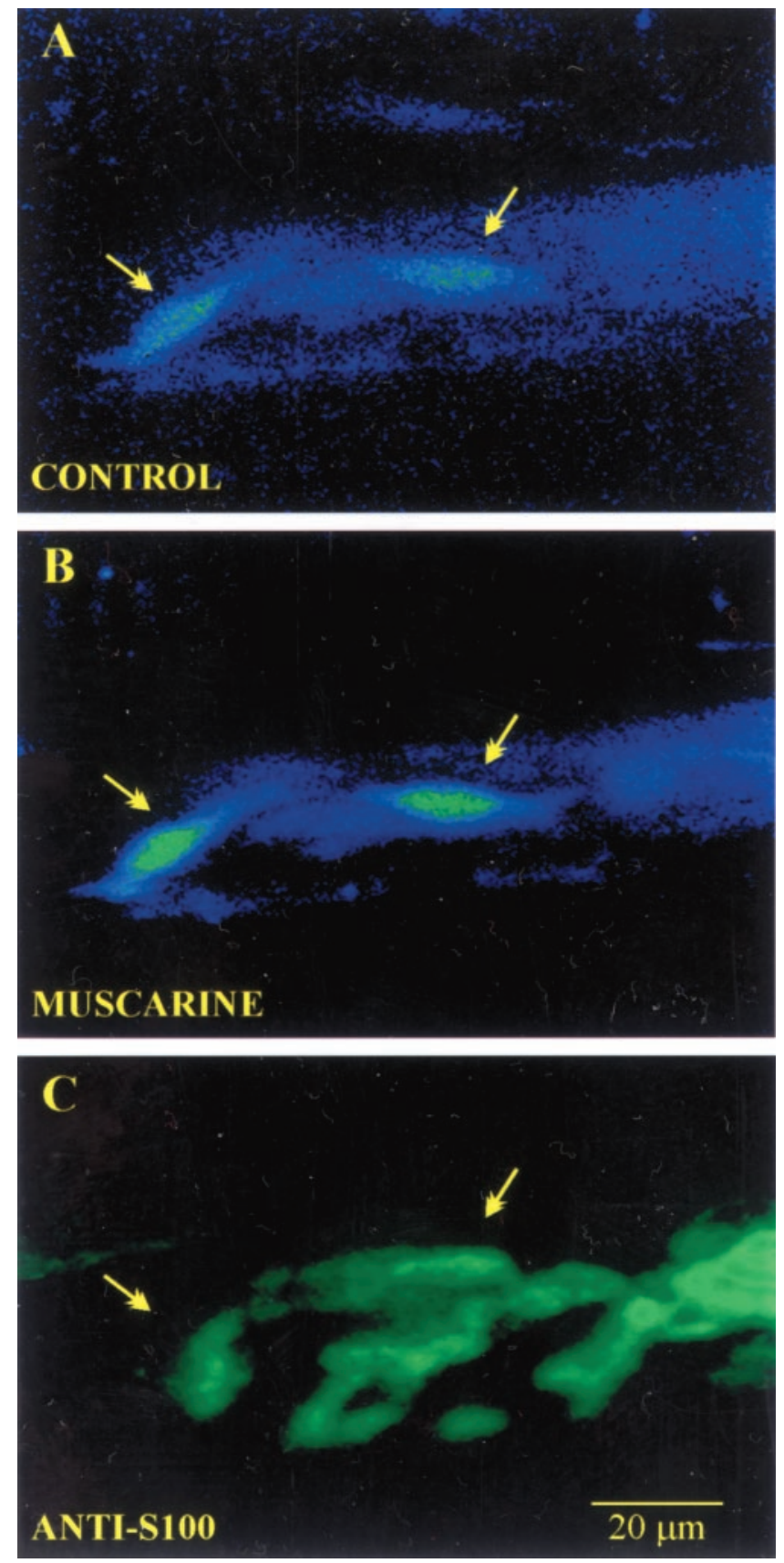

Figure 1. Identification of PSCs at the mammalian NMJ. A, False color confocal image of a mammalian NMJ loaded with the fluorescent $\mathrm{Ca}^{2+}$ indicator fluo-3 AM. The range of false colors reflects the level of $\mathrm{Ca}^{2+}$ level, where blue indicates a low level of $\mathrm{Ca}^{2+}$, and green-red indicates a high level. Two PSCs (arrows) at rest before local application of muscarine. $B$, The same PSCs as in $A$, after application of muscarine $(20 \mu \mathrm{M})$. Note the rise in fluorescence induced by muscarine. $C$, Labeling of PSCs of the same NMJ with anti-S100, a calcium binding protein used as a general marker for Schwann cells. Note that the two cells that responded to muscarine were also labeled by the S100 antibody. Scale bar, $20 \mu \mathrm{m}$.

$\mathrm{Ca}^{2+}$ response. The mean amplitude of the response was only $14 \pm 15 \% \Delta F / F(n=5)$. These results indicate that PSCs detect and are sensitive to synaptic activity. In contrast to the PSCs, and although loaded with fluo-3, no $\mathrm{Ca}^{2+}$ responses were detected from the myelinating Schwann cells present at the last myelinated segment of the motor nerve (data not shown).
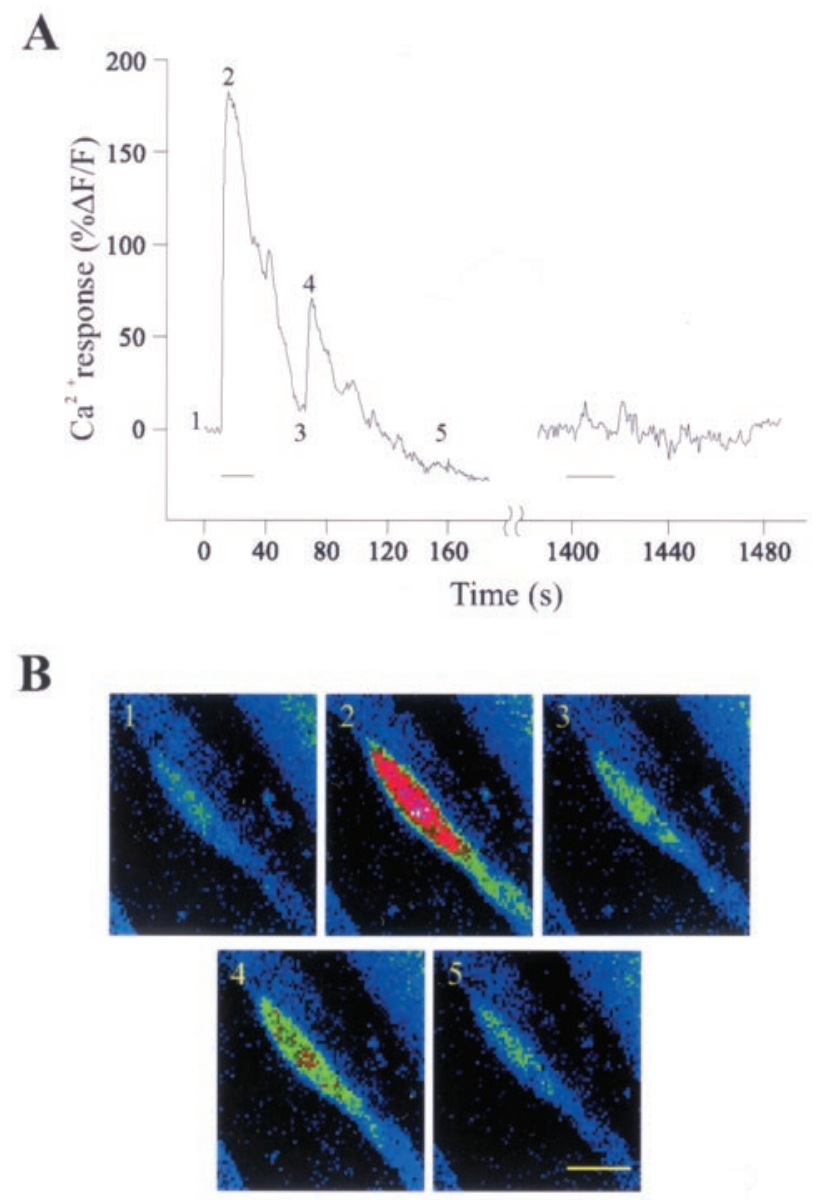

C

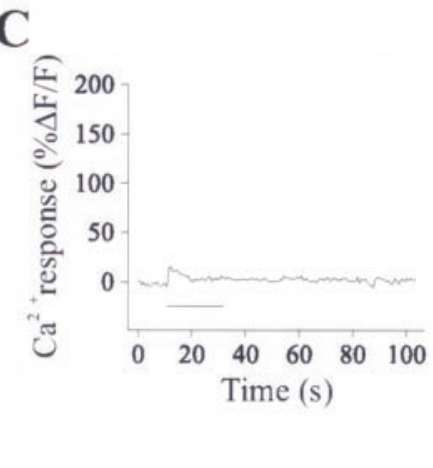

D

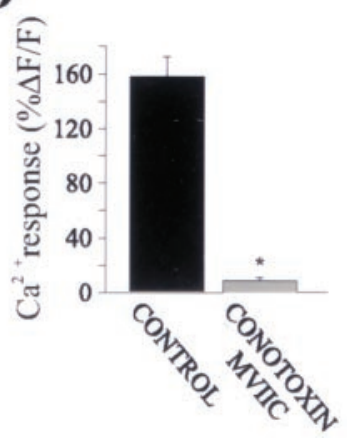

Figure 2. Nerve-evoked $\mathrm{Ca}^{2+}$ responses in PSCs. $\mathrm{Ca}^{2+}$ responses obtained using the fluorescent $\mathrm{Ca}^{2+}$ indicator fluo-3 $\mathrm{AM}$ and monitored using a Bio-Rad 600 confocal microscope. Blue indicates low level of calcium, and red indicates a high level. $A$, Changes in fluorescence $(\% \Delta F / F)$ before, during (bar), and after motor nerve stimulation $(50 \mathrm{~Hz}$, $30 \mathrm{sec}$ ). Note that relative increase in $\mathrm{Ca}^{2+}$ fluorescence to a second train of stimuli applied $20 \mathrm{~min}$ later (break in the $x$-axis) was much reduced. $B$, $\mathrm{Ca}^{2+}$ response in the same PSC as in $A$, before (1), during (2), and after (3-5) transmitter release induced by repetitive stimulation of the motor nerve $(50 \mathrm{~Hz}, 30 \mathrm{sec})$. The corresponding time at which each image was taken is illustrated on the graph in $A$ with the corresponding number of the figure above. $C$, Changes in fluorescence $(\% \Delta F / F)$ before, during (bar), and after motor nerve stimulation $(50 \mathrm{~Hz}, 30 \mathrm{sec})$ in the presence of $\omega$-conotoxin MVIIC $(1 \mu \mathrm{M})$. Note that the increase in the intensity of the fluorescence was strongly reduced when transmitter release was blocked by $\omega$-conotoxin MVIIC, a P/Q-type $\mathrm{Ca}^{2+}$ channel blocker. Different preparation than $A$ and $B . D$, Mean \pm SEM of amplitude of $\mathrm{Ca}^{2+}$ responses in PSCs elicited by nerve stimulation in the absence and in the presence of $\omega$-conotoxin MVIIC ( $p=0.001$; Student's paired $t$ test). Scale bar: $B, 10 \mu \mathrm{m}$. 


\section{Is transmitter release required to elicit $\mathrm{Ca}^{2+}$ responses?}

The response of PSCs to synaptic activity could be attributable to an increase of extracellular $\mathrm{K}^{+}$ions during high-frequency stimulation that would depolarize the cell and open voltage-gated $\mathrm{Ca}^{2+}$ channels (MacVicar, 1984; Newman, 1986; Barres et al., 1990; Robitaille et al., 1996) or to the release of neurotransmitters (Jahromi et al., 1992; Reist and Smith, 1992; Robitaille, 1995). To distinguish between the two possibilities, the $\mathrm{Ca}^{2+}$-dependent release of neurotransmitters was prevented by blocking the $\mathrm{Ca}^{2+}$ channels that trigger this process. If transmitter release is required to elicit $\mathrm{Ca}^{2+}$ responses observed in PSCs, these should be reduced in the presence of the $\mathrm{Ca}^{2+}$ channel blocker. However, $\mathrm{Ca}^{2+}$ responses in PSCs should remain unchanged if they are caused by $\mathrm{K}^{+}$accumulation. Transmitter release was blocked using the toxin $\omega$-conotoxin MVIIC ( $\omega$-CgTx), which binds irreversibly to $\mathrm{P} / \mathrm{Q}$-type $\mathrm{Ca}^{2+}$ channel. It was used at concentrations known to completely block evoked transmitter release at the mouse NMJ (Katz et al., 1996). After blockade of transmitter release by $\omega$-CgTx ( $1 \mu \mathrm{M}$; data not shown), the nerve-evoked $\mathrm{Ca}^{2+}$ signal in PSCs was on average $9 \pm 2 \% \Delta F / F(n=6)$ (Fig. $2 C$ ). This represents a reduction of $94 \%$ in the size of the $\mathrm{Ca}^{2+}$ responses in comparison to the ones obtained in the absence of $\omega$-CgTx MVIIC (Fig. 2D). Thus, substances released by the nerve terminal during evoked activity are necessary for the induction of $\mathrm{Ca}^{2+}$ responses in PSCs, suggesting that PSCs are sensitive to transmitters released during synaptic activity. The residual $\mathrm{Ca}^{2+}$ response in PSCs in the presence of $\omega$-CgTx MVIIC is likely attributable to the depolarization of the cell caused by $\mathrm{K}^{+}$accumulation during synaptic activity (Jahromi et al., 1992; Robitaille et al., 1996).

\section{Can ACh trigger $\mathrm{Ca}^{2+}$ responses at the mammalian NMJ?}

Our data indicate that neurotransmitter substances released during synaptic activity are necessary to elicit fully developed $\mathrm{Ca}^{2+}$ responses in PSCs. As primary candidates, ACh and ATP appear particularly important because $\mathrm{ACh}$ is the main neurotransmitter at this synapse and ATP is coreleased at an equimolar concentration (Silinsky, 1975; Smith, 1991). If substances such as the cotransmitters ATP and ACh released by the active nerve terminal induce PSC Ca ${ }^{2+}$ signals, then application of these substances alone should mimic the effects induced by stimulation of the motor nerve.

The ability of PSCs to respond to ACh applied locally was examined first. ACh was applied directly by micropressure (5-10 PSI) to selected PSCs. As shown in Figure $3 A$, local application of $\mathrm{ACh}(20 \mu \mathrm{M})$ induced a $\mathrm{Ca}^{2+}$ response in all PSCs tested $(350 \pm$ $18 \% \Delta F / F ; n=10)$. Because the $\mathrm{Ca}^{2+}$ response obtained by stimulation of the motor nerve decreased during consecutive trains of stimuli (Fig. $2 A$ ), we wondered whether the $\mathrm{Ca}^{2+}$ responses induced by local applications of $\mathrm{ACh}$ would also be susceptible to rundown. Indeed, a second application of ACh evoked responses that were significantly smaller than the first ones $(249 \pm 19 \% \Delta F / F$ vs $357 \pm 30 \% \Delta F / F$ for control; $n=5 ; p=$ 0.0006 ; Student's paired $t$ test) (Fig. $3 A$, break in the $x$-axis).

We next investigated whether the rise in intracellular $\mathrm{Ca}^{2+}$ triggered by $\mathrm{ACh}$ was attributable to an entry of extracellular $\mathrm{Ca}^{2+}$ or caused by the release from intracellular stores. To distinguish between the two possibilities, extracellular $\mathrm{Ca}^{2+}$ was removed and replaced by a $5 \mathrm{mM} \mathrm{Mg}^{2+}$ physiological solution, and the ability of PSCs to respond to locally applied ACh was
A

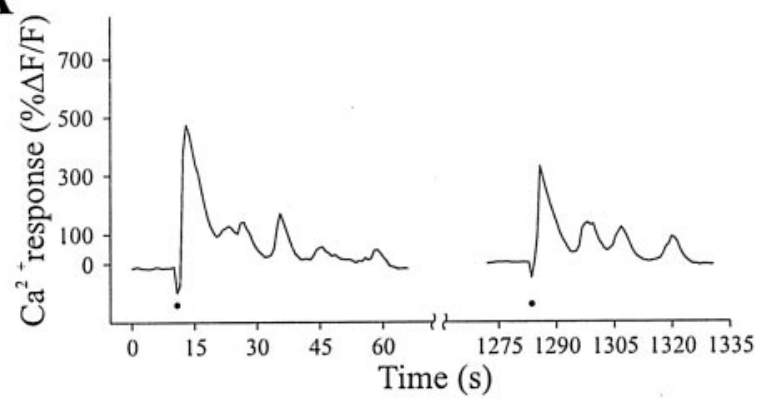

B
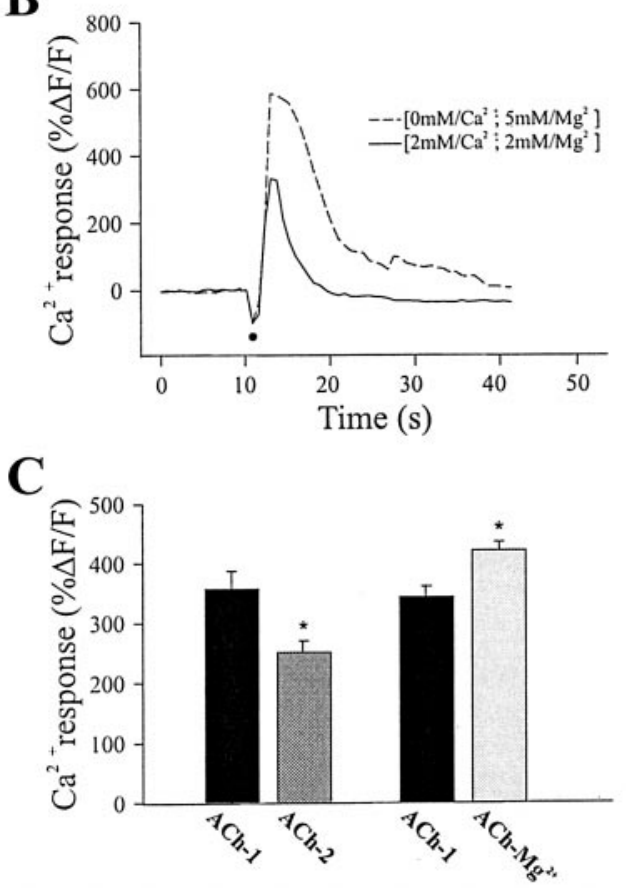

Figure 3. $\mathrm{Ca}^{2+}$ responses of PSCs to local application of ACh. $A$, Changes in fluorescence over time caused by the local application of ACh $(20 \mu \mathrm{M})$ for $200 \mathrm{msec}$ in normal physiological solution. Application of ACh caused a Ca ${ }^{2+}$ response in all PSCs studied. A second application 20 min later (break in the $x$-axis) induced smaller changes in fluorescence. $B$, Changes in fluorescence caused by the local application of ACh $(20 \mu \mathrm{M}$, $200 \mathrm{msec}$ ) in the presence (solid line) and in the absence (dashed line) of external $\mathrm{Ca}^{2+}$ for the same PSCs. $\mathrm{Ca}^{2+}$ was replaced by $5 \mathrm{~mm} \mathrm{Mg}{ }^{2+}$. Note that ACh application induced larger changes in fluorescence in the absence of external $\mathrm{Ca}^{2+} . C$, Mean \pm SEM of relative changes in $\mathrm{Ca}^{2+}$ responses induced by a first and a second application of ACh $(20 \mu \mathrm{M})$ and for application of ACh in absence of external $\mathrm{Ca}^{2+}$.

tested again. As shown in Figure $3 B$, on all PSCs tested, $\mathrm{Ca}^{2+}$ responses were elicited by a local application of $\mathrm{ACh}$ in $0 \mathrm{Ca}^{2+} / 5$ $\mathrm{Mg}^{2+} 20$ min after a first application in normal $\mathrm{Ca}^{2+}$, indicating that $\mathrm{ACh}$ induced the release of $\mathrm{Ca}^{2+}$ from internal stores. Surprisingly, the size of $\mathrm{Ca}^{2+}$ responses induced by $\mathrm{ACh}$ in 0 $\mathrm{Ca}^{2+} / 5 \mathrm{Mg}^{2+}$ was significantly larger than the size of the responses obtained in the presence of extracellular $\mathrm{Ca}^{2+}(421 \pm$ $15 \% \Delta F / F$ vs $343 \pm 22 \% \Delta F / F$ for control; $n=5 ; p=0.001$; Student's paired $t$ test) (Fig. $3 B, C$ ). This indicates that, although the contribution of internal stores is essential for the induction of $\mathrm{Ca}^{2+}$ responses by $\mathrm{ACh}$, the presence of extracellular $\mathrm{Ca}^{2+}$ downregulates the activation of the release of $\mathrm{Ca}^{2+}$ from internal stores by ACh (Fig. 3C). 
A

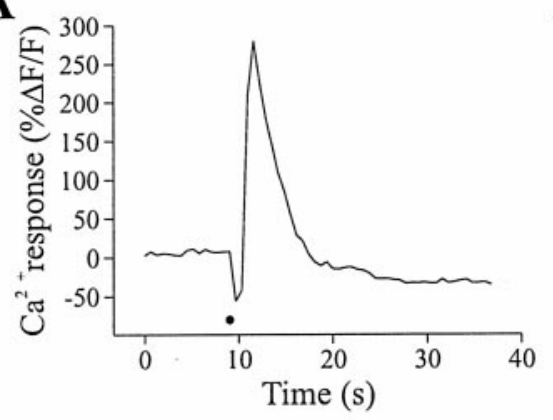

C

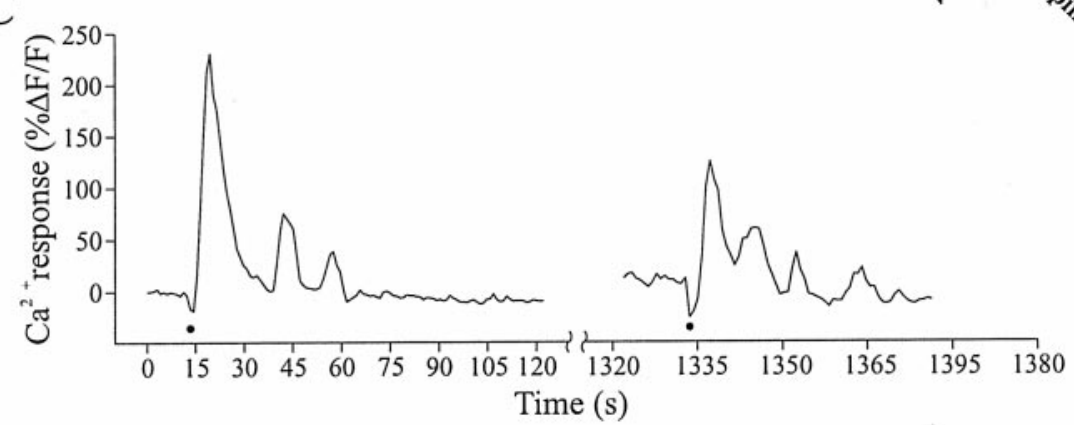

D

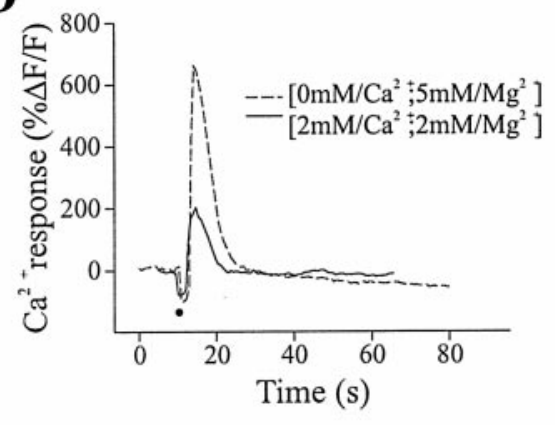

B

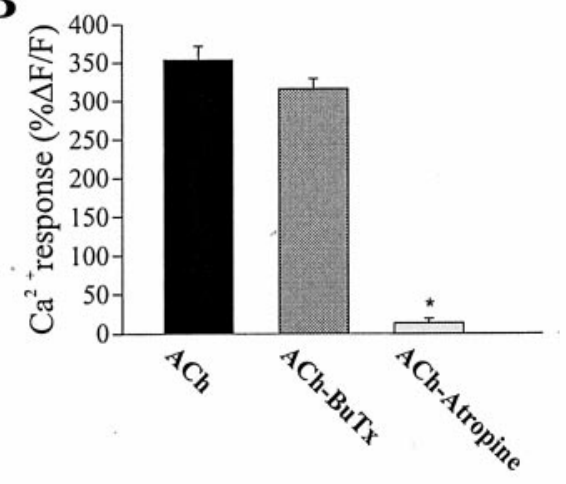

Figure 4. $\mathrm{Ca}^{2+}$ responses of PSCs to local application of muscarine. $A$, Changes in fluorescence caused by the local application of acetylcholine ( 20 $\mu \mathrm{M}, 200 \mathrm{msec})$ in the presence of $\alpha$-BuTx $(20 \mu \mathrm{M})$. The increase in the intensity of fluorescence induced by the local application of ACh was unaffected by $\alpha$-BuTx. $B$, Comparison of mean \pm SEM of $\mathrm{Ca}^{2+}$ responses induced by $\mathrm{ACh}$ alone, in the presence of $\alpha$-BuTx, and in the presence of atropine. $C$, Changes in fluorescence over time caused by the local application of muscarine $(20 \mu \mathrm{M})$ for $200 \mathrm{msec}$ in normal physiological solution. Application of muscarine caused a $\mathrm{Ca}^{2+}$ response in all PSCs studied. A second application 20 min later (break in the $x$-axis) induced smaller changes in fluorescence. $D$, Changes in fluorescence caused by the local application of muscarine $(20 \mu \mathrm{M})$ in the presence (solid line) and in the absence (dashed line) of external $\mathrm{Ca}^{2+}$ for the same PSCs. $\mathrm{Ca}^{2+}$ was replaced by $5 \mathrm{~mm} \mathrm{Mg}^{2+}$. Note that muscarine induced larger changes in fluorescence in the absence of external $\mathrm{Ca}^{2+}$. E, Comparison of mean \pm SEM of $\mathrm{Ca}^{2+}$ responses induced by a first and a second application of muscarine (left) and application of muscarine in presence and absence of external $\mathrm{Ca}^{2+}$ (right).

\section{Muscarinic receptors mediate ACh effects}

For a better understanding of the role of glial cells at the synapse, it is necessary to further characterize the cellular receptors and functions of these glial cells. To determine the type of cholinergic receptors involved, we first used $\alpha$-BuTx, an antagonist of the nicotinic ACh receptors (AChRs). If $\mathrm{Ca}^{2+}$ responses to $\mathrm{ACh}$ were caused by nicotinic AChRs, they should be blocked by the nicotinic cholinergic antagonist $\alpha$-BuTx. To test the effectiveness of $\alpha$-BuTx $(20 \mu \mathrm{M})$, preparations were perfused with the antagonist for at least 30 min before local application of ACh on PSCs was performed. This concentration blocks completely the activity of the nicotinic postsynaptic receptors at the frog NMJ (Jahromi et al., 1992). As shown in Figure 4, $A$ and $B$, the ability of PSCs to respond to ACh was not affected by the presence of $\alpha$-BuTx. Indeed, $\mathrm{Ca}^{2+}$ responses to $\mathrm{ACh}$ were still obtained in the presence of the toxin in all cells tested, and the size of the $\mathrm{Ca}^{2+}$ responses $(317 \pm 13 \% \Delta F / F ; n=5)$ was not significantly different from the control responses obtained on the same cells before the application of $\alpha$-BuTx (Student's paired $t$ test; $p>0.05$ ).

The lack of effect of the nicotinic antagonist suggests that PSC AChRs are not nicotinic but rather, that the $\mathrm{Ca}^{2+}$ response induced by ACh was likely because of the activation of muscarinic receptors. If this were the case, muscarinic antagonists such as atropine should prevent $\mathrm{Ca}^{2+}$ responses to $\mathrm{ACh}$. As shown in Figure $4 B$, the presence of atropine almost completely abolished $\mathrm{Ca}^{2+}$ responses elicited by $\mathrm{ACh}$ in all cells tested $(n=15)$. The mean size of the responses was only $14 \pm 6 \% \Delta F / F$, which is significantly smaller than the responses obtained from the same cells by a first application of ACh (Student's paired $t$ test; $p=$ 0.001).

We next investigated the ability of the muscarinic agonist muscarine to evoke $\mathrm{Ca}^{2+}$ responses. Local application of muscarine $(20 \mu \mathrm{M})$ induced a $\mathrm{Ca}^{2+}$ response in all cells on which it was applied $(n=15)$ with a mean amplitude of $275 \pm 43 \% \Delta F / F$ (Fig. $4 C$ ). Similar to our observation using ACh, a second application of muscarine caused $\mathrm{Ca}^{2+}$ elevations that were significantly smaller than the ones obtained with a first application (150 $\pm 12 \% \Delta F / F ; n=9 ; p=0.02$; Student's paired $t$ test) (Fig. $4 C, E)$.

If indeed $\mathrm{ACh}$-induced $\mathrm{Ca}^{2+}$ responses are solely mediated by muscarinic receptors, muscarine-induced $\mathrm{Ca}^{2+}$ responses in PSCs should also be mediated by internal stores with a regulation by extracellular $\mathrm{Ca}^{2+}$. This was tested by measuring $\mathrm{Ca}^{2+}$ responses in the absence of external $\mathrm{Ca}^{2+}$ where muscles were perfused with $0 \mathrm{mM} \mathrm{Ca}^{2+}$ and $5 \mathrm{mM} \mathrm{Mg}^{2+}$ for $30 \mathrm{~min}$. In these conditions, application of muscarine $(20 \mu \mathrm{M})$ evoked $\mathrm{Ca}^{2+}$ re- 
A

Figure 5. $\mathrm{Ca}^{2+}$ responses of PSCs to local application of ATP and adenosine. $A$, Changes in fluorescence over time caused by the local application of ATP $(20 \mu \mathrm{M})$ for $200 \mathrm{msec}$ in normal physiological solution. Application of ATP caused a $\mathrm{Ca}^{2+}$ response in all PSCs studied. A second application 20 min later (break in the $x$-axis) induced smaller changes in fluorescence. $B$, Changes in fluorescence over time caused by the local application of adenosine $(20 \mu \mathrm{M})$ for $200 \mathrm{msec}$ in normal physiological solution. Application of adenosine caused a $\mathrm{Ca}^{2+}$ response in all PSCs studied. A second application 20 min later (break in the $x$-axis) induced smaller changes in fluorescence. $C$, Changes in fluorescence caused by the local application of ATP $(20 \mu \mathrm{M}$, $200 \mathrm{msec}$ ) in the presence (solid line) and in the absence (dashed line) of external $\mathrm{Ca}^{2+}$ for the same PSCs. Note that ATP induced larger changes in fluorescence in the absence of external $\mathrm{Ca}^{2+} . D$, Changes in fluorescence caused by the local application of adenosine in the presence (solid line) and in the absence (dashed line) of external $\mathrm{Ca}^{2+}$ for the same PSCs. Note that adenosine induced larger changes in fluorescence in the absence of external $\mathrm{Ca}^{2+} . E$, Comparison of mean \pm SEM of $\mathrm{Ca}^{2+}$ responses induced by a first and a second application of ATP (left) and the application of ATP in the presence and in the absence of external $\mathrm{Ca}^{2+}$ (right).F, Comparison of mean \pm SEM of $\mathrm{Ca}^{2+}$ responses induced by a first and a second application of adenosine (left) and application of adenosine in the presence and in the absence of external $\mathrm{Ca}^{2+}$ (right).

E
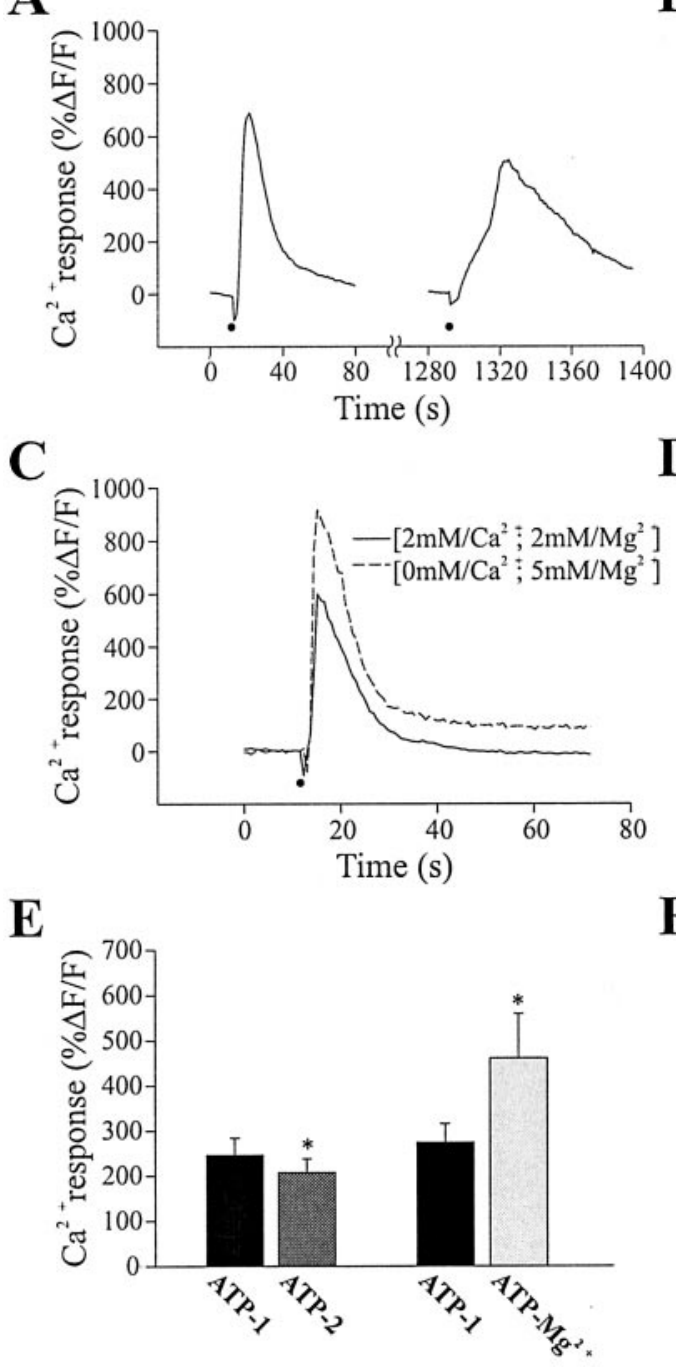

B

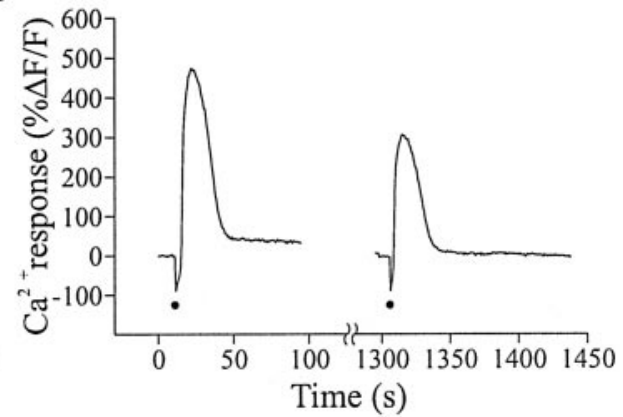

D

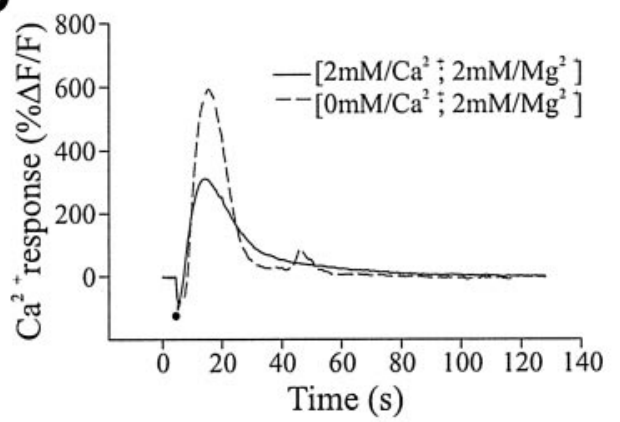

F

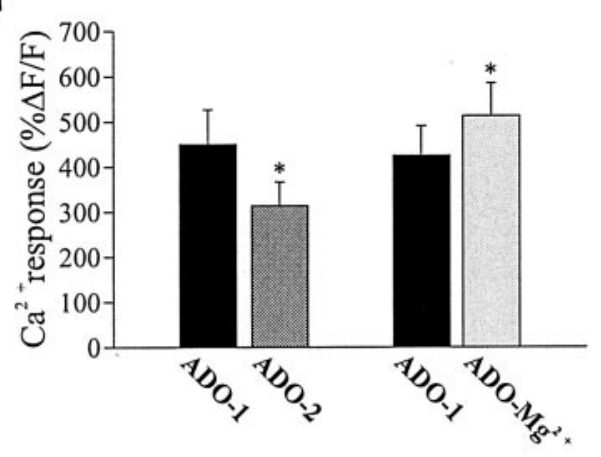

sponses that were significantly larger $(360 \pm 30 \% \Delta F / F ; n=6$; $p=0.003$; Student's paired $t$ test) (Fig. $4 D, E$ ) than the responses obtained after a first application on the same cell in the presence of $\mathrm{Ca}^{2+}$. These results indicate that, similarly to ACh-mediated $\mathrm{Ca}^{2+}$ responses, $\mathrm{Ca}^{2+}$ responses induced by muscarine were attributable to the release of $\mathrm{Ca}^{2+}$ from internal stores and regulated by extracellular $\mathrm{Ca}^{2+}$. As a whole, these data indicate that AChRs of the mammalian PSCs are of the muscarinic type.

\section{Can ATP and adenosine trigger $\mathrm{Ca}^{2+}$ responses at the mammalian NMJ?}

At the frog NMJ, application of ATP to PSCs induces the release of $\mathrm{Ca}^{2+}$ from internal stores (Jahromi et al., 1992; Robitaille, 1995) because of the activation of $\mathrm{P}_{2 \mathrm{X}}$ and $\mathrm{P}_{2 \mathrm{Y}}$ receptors (Robitaille, 1995). To examine the involvement of endogenous purines in the modulation of mammalian PSCs in situ and to test whether ATP and adenosine can activate PSCs, changes in intracellular $\mathrm{Ca}^{2+}$ induced by local application of ATP and adenosine were monitored.

ATP $(20 \mu \mathrm{M})$ induced $\mathrm{Ca}^{2+}$ responses in all PSCs tested (299 $\pm 30 \% \Delta F / F ; n=41)$ (Fig. $5 A)$, whereas local applications of adenosine $(20 \mu \mathrm{M})$ resulted in a rise of fluorescence of $441 \pm 51 \%$ $\Delta F / F$ also in all PSCs tested $(n=19)$ (Fig. $5 B)$. A second application of ATP evoked responses that were significantly smaller than the first response $(207 \pm 30 \% \Delta \mathrm{F} / \mathrm{F}$ vs $246 \pm 38 \%$ $\Delta \mathrm{F} / \mathrm{F}$ for control; $n=8 ; p=0.0004$ ) (Fig. $5 A$ ). Similarly, a second application of adenosine evoked responses that were significantly smaller than the first response $(314 \pm 52 \% \Delta \mathrm{F} / \mathrm{F}$ vs $450 \pm 77 \%$ $\Delta \mathrm{F} / \mathrm{F} ; n=11 ; p=0.0004$; Student's paired $t$ test) (Fig. $5 B$ ).

In most glial cells (Salter and Hicks, 1994), including PSCs at the amphibian NMJ (Jahromi et al., 1992; Robitaille, 1995), purinergic agonists elicit an elevation in intracellular $\mathrm{Ca}^{2+}$ that involves the release of $\mathrm{Ca}^{2+}$ from internal stores. This possibility was tested by replacing extracellular $\mathrm{Ca}^{2+}$ ions by $\mathrm{Mg}^{2+}(5 \mathrm{~mm})$. As shown in Figure $5 C, \mathrm{Ca}^{2+}$ responses induced by local application of ATP still induced $\mathrm{Ca}^{2+}$ responses in all mammalian PSCs tested, even in the absence of $\mathrm{Ca}^{2+}$ in the solution, pointing toward a critical role of $\mathrm{Ca}^{2+}$ internal stores in the production of the $\mathrm{Ca}^{2+}$ responses. On average, the amplitude of the $\mathrm{Ca}^{2+}$ responses was $461 \pm 98 \% \Delta F / F$. However, similar to AChinduced $\mathrm{Ca}^{2+}$ responses, local application of ATP in absence of extracellular $\mathrm{Ca}^{2+}$ evoked $\mathrm{Ca}^{2+}$ responses that were significantly larger than the ones evoked by a first application of ATP on the same cells $(273 \pm 42 \% \Delta F / F$ for control; $n=11 ; p=0.02$; Student's paired $t$ test) (Fig. $5 C$ ). Similarly, adenosine also caused $\mathrm{Ca}^{2+}$ responses in absence of external $\mathrm{Ca}^{2+}$ that were significantly larger than those obtained in the presence of $\mathrm{Ca}^{2+}(497 \pm$ 
$72 \% \Delta F / F$ vs $428 \pm 6 \% \Delta F / F ; n=8 ; p=0.001 ;$ Student's paired $t$ test) (Fig. 5D). These results indicate that PSCs at the mammalian NMJ detect adenosine and ATP and that these substances induce the release of $\mathrm{Ca}^{2+}$ from internal stores via a mechanism that is negatively regulated by external $\mathrm{Ca}^{2+}$ (Fig. 5E,F).

\section{Are purinergic receptors present on PSCs?}

To verify the presence of adenosine and ATP receptors on the mammalian PSCs, the ability of these agonists to evoke $\mathrm{Ca}^{2+}$ responses in PSCs was tested in the presence of antagonists for P2 and $\mathrm{P} 1$ receptors. Suramin, a nonselective $\mathrm{P} 2$ receptor antagonist was first tested. $\mathrm{Ca}^{2+}$ responses induced by ATP should be abolished in the presence of this antagonist if they are mediated by the activation of $\mathrm{P} 2$ receptors. After eliciting a $\mathrm{Ca}^{2+}$ response by ATP on PSCs, the preparations were perfused with suramin $(100 \mu \mathrm{M})$, and the ATP was applied locally on the same cells. As shown in Figure $6, \mathrm{Ca}^{2+}$ responses were still induced by local applications of ATP $(20 \mu \mathrm{M})(289 \pm 34 \% \Delta F / F ; n=6)$ (Fig. $6 A)$, and the average amplitude of the responses was not significantly different from responses evoked by the same cells before application of the antagonist (Student's paired $t$ test; $p=0.239$ ). It is unlikely that the lack of effect was attributable to the inability of suramin to block $\mathrm{P} 2$ receptors because the same solution blocked ATP-induced responses at PSCs of amphibian NMJs (Robitaille, 1995). Hence, this result suggests that ATP raised intracellular $\mathrm{Ca}^{2+}$ by mechanisms that do not activate $\mathrm{P} 2$ receptors.

However, $\mathrm{Ca}^{2+}$ responses evoked by adenosine were almost completely abolished in the presence of CPT $(10 \mu \mathrm{M})$, an A1 receptor antagonist $(32 \pm 6 \% \Delta F / F ; n=5$ ) (Fig. $6 B)$. This value was significantly smaller than the responses obtained on the same cells before the application of the antagonist in the perfusate (Student's paired $t$ test; $p=0.001$ ). This suggests that the adenosine-induced $\mathrm{Ca}^{2+}$ responses were mediated by the activation of $\mathrm{A} 1$ receptors.

Ectoenzymes present in the synaptic cleft (Salter et al., 1993; Ziganshin et al., 1993) will cause the dephosphorylation of ATP and lead to adenosine formation. Because adenosine appears as an active substance at the mammalian NMJ and because ATP can be exogenously degraded into adenosine, it is possible that the $\mathrm{Ca}^{2+}$ responses evoked by local applications of ATP were attributable to the indirect activation of A1 receptors. This possibility was tested by locally applying ATP in the presence of CPT. As shown in Figure $6 C$, the presence of CPT $(10-20 \mu \mathrm{M})$ in the perfusion did not block $\mathrm{Ca}^{2+}$ responses induced by ATP. The average amplitude of the $\mathrm{Ca}^{2+}$ responses was $384 \pm 86 \% \Delta F / F$ $(n=7)$, which is not significantly different from control (ANOVA; $p>0.05$ ). These results suggest that the action of ATP was not mediated by an indirect activation of A1 receptors and, hence, would be produced by other ATP-dependent mechanisms.

\section{Endogenous $\mathrm{ACh}$ and adenosine mediate nerve- evoked $\mathrm{Ca}^{2+}$ responses in PSCs}

Our results indicate that functional muscarinic and A1 adenosine receptors are present on PSCs of the mammalian NMJ. We next wondered whether $\mathrm{ACh}$ and adenosine released by the presynaptic terminal during synaptic activity could mediate the activation of PSCs and the triggering of the nerve stimulation-evoked $\mathrm{Ca}^{2+}$ responses in PSCs. Because nerve-evoked $\mathrm{Ca}^{2+}$ responses decrease during consecutive trains of stimuli (Fig. $2 A$ ), the effects of the two different blockers on nerve-evoked $\mathrm{Ca}^{2+}$ responses were tested on different preparations, and each preparation was stimulated only once.
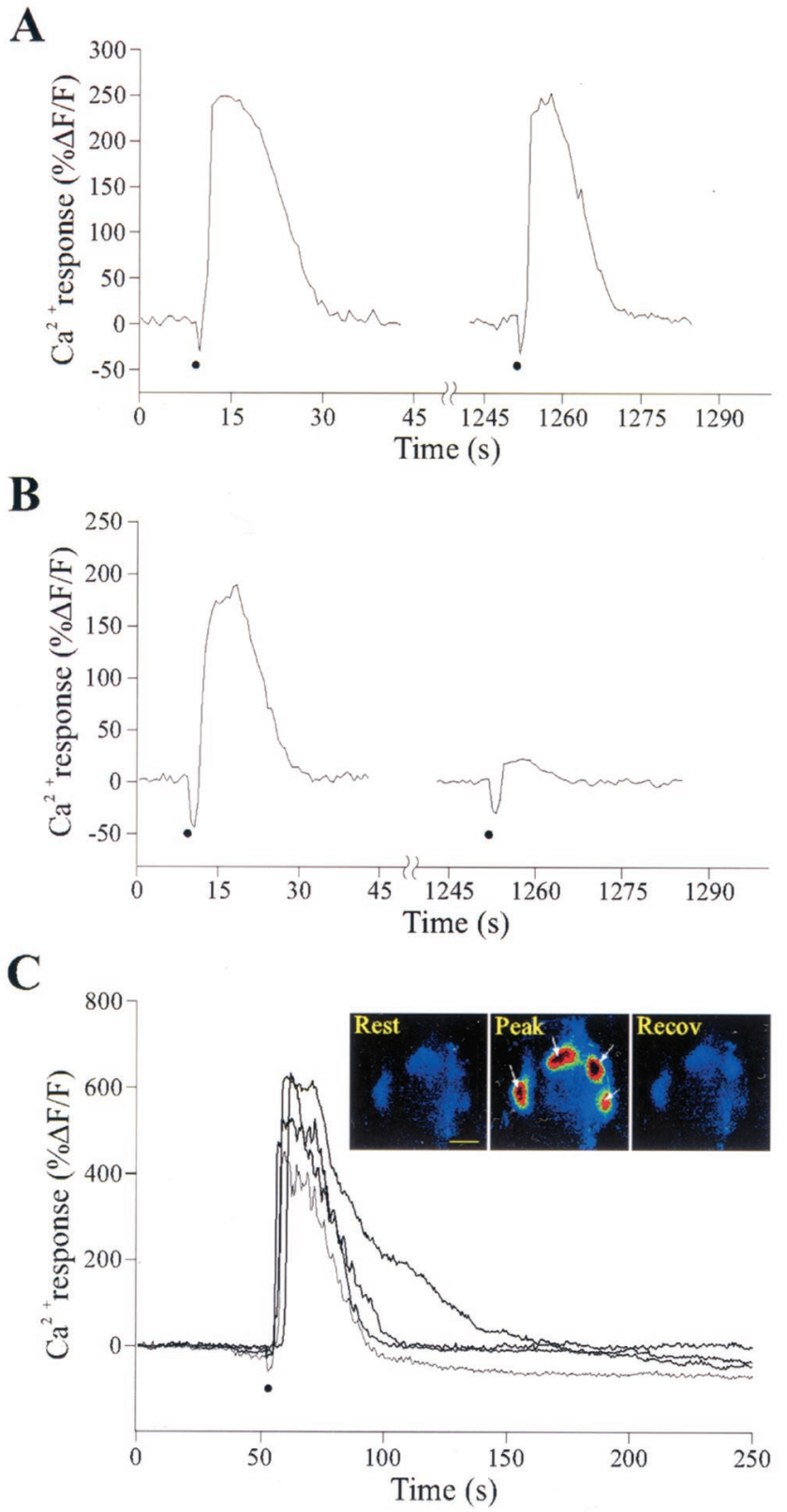

Figure 6. $\mathrm{Ca}^{2+}$ responses of PSCs to local application of ATP and adenosine in presence of purinergic antagonists. $A$, Changes in fluorescence caused by the local application of ATP before and after (break in the $x$-axis) a 20 min perfusion with suramin $(100 \mu \mathrm{M})$, a nonspecific P2 antagonist. Note that the increase in the intensity of fluorescence induced by the local application of ATP was unaffected by the presence of suramin. $B$, Changes in fluorescence caused by the local application of adenosine before and after a $20 \mathrm{~min}$ perfusion with $\mathrm{CPT}(10 \mu \mathrm{M}) . C$, Changes in fluorescence in four PSCs of an NMJ caused by the local application of ATP in the presence of the A1 receptor antagonist CPT $(20 \mu \mathrm{M})$. Inset, False color confocal images of the four PSCs at rest (Rest), at the peak of the $\mathrm{Ca}^{2+}$ response (Peak), and after recovery (Recov). Note that the increase in the intensity of fluorescence induced by the local application of ATP was unaffected by the presence of CPT. Scale bar, $10 \mu \mathrm{m}$.

We first examined the impact of blockade of ACh receptors on nerve-evoked $\mathrm{Ca}^{2+}$ responses. The blockade of $\mathrm{ACh}$ receptors with atropine $(20 \mu \mathrm{M})$ greatly reduced the amplitude of $\mathrm{Ca}^{2+}$ responses induced by stimulation of the motor nerve to $33 \pm 3 \%$ $\Delta F / F(n=5)($ Fig. $7 A)$. This value is significantly smaller than the 
A

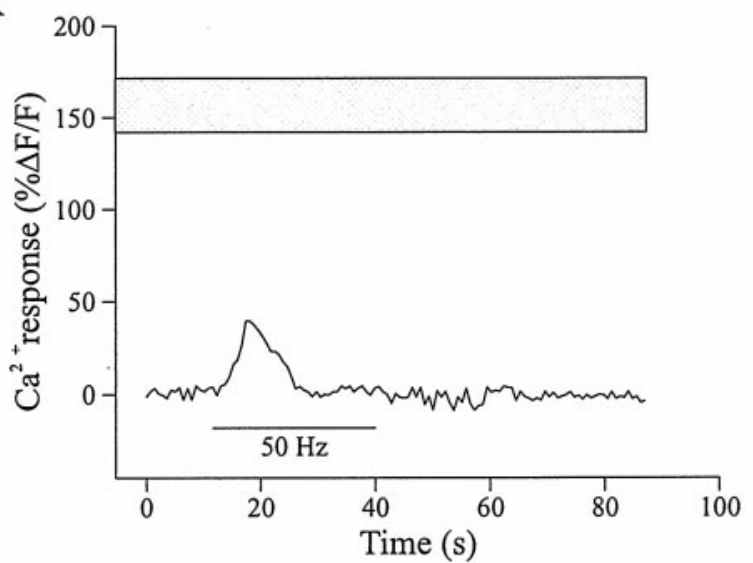

B

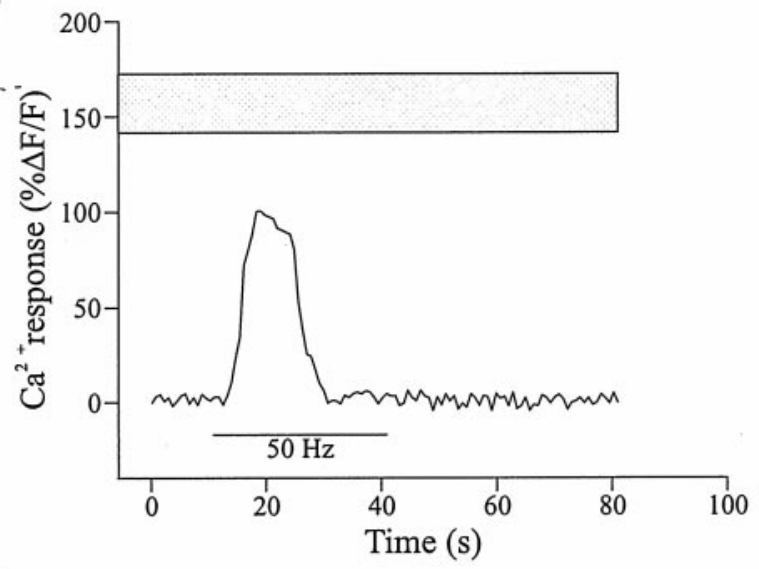

C

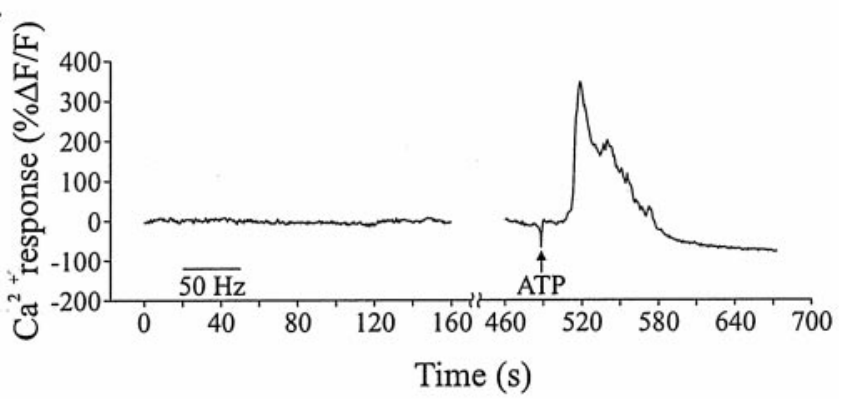

Figure 7. Nerve-evoked $\mathrm{Ca}^{2+}$ responses in PSCs in presence of atropine and CPT. $A$, Changes in fluorescence of a PSC before, during (bar), and after repetitive motor nerve stimulation $(50 \mathrm{~Hz}, 30 \mathrm{sec})$ after $20 \mathrm{~min}$ perfusion with atropine $(20 \mu \mathrm{M})$, a muscarinic antagonist. The boxed gray zone illustrates the mean \pm SEM of nerve-evoked $\mathrm{Ca}^{2+}$ responses obtained from the 10 PSCs in absence of any antagonists (Fig. 2A). $B$, Changes in fluorescence of a PSC before, during (bar), and after repetitive motor nerve stimulation $(50 \mathrm{~Hz}, 30 \mathrm{sec})$ after $20 \mathrm{~min}$ perfusion with CPT $(10 \mu \mathrm{M})$, an A1 antagonist. The gray zone illustrates the mean \pm SEM of nerve-evoked $\mathrm{Ca}^{2+}$ responses obtained from the 10 cells in absence of any antagonists. $C$, Changes in fluorescence of a PSC before, during (bar), and after repetitive motor nerve stimulation $(50 \mathrm{~Hz}, 30 \mathrm{sec})$ after 20 min perfusion with CPT $(10 \mu \mathrm{M})$ and atropine $(20 \mu \mathrm{M})$. Note that the repetitive stimulation of the motor nerve did not induce any $\mathrm{Ca}^{2+}$ response in the PSC. After a recovery period of $5 \mathrm{~min}$, ATP $(20 \mu \mathrm{M})$ was locally applied on the PSC, which elicited a $\mathrm{Ca}^{2+}$ response.

one obtained in the absence of atropine $(157 \pm 15 \% \Delta F / F$; one-way ANOVA, $p<0.05$ ) (Fig. $7 A$, gray zone), indicating that the activation of $\mathrm{ACh}$ receptors was necessary for optimal $\mathrm{Ca}^{2+}$ responses and, hence, activation of PSCs during synaptic trans- mission. The remnant of $\mathrm{Ca}^{2+}$ responses still induced by synaptic activity was not caused by the inefficacy of atropine because local applications of muscarine on the same cells tested in these experiments could not elicit any $\mathrm{Ca}^{2+}$ responses (data not shown).

We next tested the impact of the $\mathrm{A} 1$ antagonist $\mathrm{CPT}$ on $\mathrm{Ca}^{2+}$ responses evoked by stimulation of the motor nerve. As shown in Figure $7 B, \mathrm{Ca}^{2+}$ responses were reduced to $98 \pm 6 \% \Delta F / F(n=$ 6) (Fig. $7 B$ ) in the presence of CPT. Although the reduction in the size of $\mathrm{Ca}^{2+}$ responses was more modest than the effect of the muscarinic antagonist, the size of the $\mathrm{Ca}^{2+}$ responses was significantly smaller than the control ones (one-way ANOVA; $p<$ 0.05) (Fig. 7B, gray zone). This indicates that the activation of adenosine receptors is important to generate the $\mathrm{Ca}^{2+}$ responses induced by nerve-evoked transmitter release. The partial blockade of the responses was not attributable to the inefficacy of CPT to antagonize the A1 receptors because local application of adenosine on the same cells did not induce any $\mathrm{Ca}^{2+}$ responses (data not shown).

Finally, we tested the impact on $\mathrm{Ca}^{2+}$ responses of both the muscarinic and $\mathrm{A} 1$ receptor antagonists together. As shown in Figure $7 C, \mathrm{Ca}^{2+}$ responses were primarily reduced in the presence of the two antagonists in which the mean $\mathrm{Ca}^{2+}$ response was only $22 \pm 8 \%(N=4 ; n=8)$. This value is significantly different from the mean response obtained in control condition (i.e., without any antagonist; one-way ANOVA, $p<0.05$ ). The remaining $\mathrm{Ca}^{2+}$ elevation is consistent with the $\mathrm{Ca}^{2+}$ response observed when transmitter release was blocked using $\omega$-CgTx MVIIC, possibly because of the depolarization of PSCs by $\mathrm{K}^{+}$accumulation during repetitive nerve stimulation. The inability to elicit $\mathrm{Ca}^{2+}$ responses was not caused by a lack of cell responsivity because local application of ATP (brake in $x$-axis) induced $\mathrm{Ca}^{2+}$ responses in all cells tested $(N=3 ; n=7)$.

\section{DISCUSSION}

We present here direct evidence that mammalian PSCs in situ respond to the release of neurotransmitters induced by stimulation of the motor nerve, as indicated by an elevation of intracellular $\mathrm{Ca}^{2+}$ level. This elevation originated mainly from the release of $\mathrm{Ca}^{2+}$ from internal stores and muscarinic and adenosine A1 receptors are the main two receptor systems involved in the communication between the nerve terminal and the PSCs. Furthermore, extracellular $\mathrm{Ca}^{2+}$ negatively affects the ability of PSCs to respond to neurotransmitters. It is concluded that, like glial cells at other synapses, synapse-glia interactions are also taking place at the mammalian NMJ but with particularities associated with this synapse.

\section{Cholinergic receptor on the mammalian PSCs}

When expressed by glial cells, including PSCs of the amphibian NMJ (Robitaille et al., 1997), cholinergic receptors have always been determined to be of the muscarinic type, mainly linked to internal $\mathrm{Ca}^{2+}$ stores regulated by an inositol 1,4,5-trisphosphate receptor (Hamprecht, 1986). Here we show that PSCs of the mammalian NMJ are no exception and that the cholinergic receptors are of the muscarinic type as indicated by the lack of effects of nicotinic antagonists and by the ability of muscarine to induce $\mathrm{Ca}^{2+}$ responses, whereas atropine blocked ACh-induced responses. The blockade of $\mathrm{Ca}^{2+}$ responses by the nonspecific muscarinic antagonist atropine also indicates that PSCs of the mammalian NMJ, unlike the ones at the amphibian NMJ, express a typical muscarinic pharmacology (Robitaille et al., 1997). Moreover, muscarinic-dependent $\mathrm{Ca}^{2+}$ responses in glial cells also 
Table 1. Comparison of the properties of PSCs at mammalian and amphibian NMJs

\begin{tabular}{|c|c|c|c|c|c|c|c|}
\hline & Cholinergic receptors & $\begin{array}{l}\text { Adenosine } \\
\text { receptors }\end{array}$ & ATP receptors & $\mathrm{Ca}^{2+}$ mechanisms & $\mathrm{Ca}^{2+}$ regulation & Oscillation & Rundown \\
\hline Mouse NMJ & Muscarinic & $\mathrm{A}_{1}$ & No & Internal stores & Negative regulation & Yes & Very steep \\
\hline Frog NMJ & Muscarinic, not M1-M5 & $\mathrm{A}_{1}$ & $\begin{array}{l}\mathrm{P} 2_{\mathrm{X}} \\
\mathrm{P} 2_{\mathrm{Y}}\end{array}$ & Internal stores; $\mathrm{IP}_{3} \mathrm{R}$ & No & No & Gradual \\
\hline
\end{tabular}

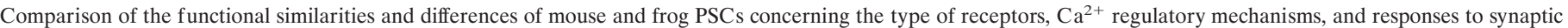
transmission evoked by nerve stimulation.

share another characteristic, that is, the rundown of the response after repetitive applications of cholinergic agonists (Dave et al., 1991; Jahromi et al., 1992; Robitaille et al., 1997).

\section{Purinergic receptors on the mammalian PSCs}

It is now established that ATP is released during synaptic transmission (Smith, 1991; Zimmermann, 1994) and is involved in intercellular signaling in various systems (Sneddon and Burnstock, 1984; Benham, 1989; Salter and Hicks, 1994; Zimmermann, 1994; Lyons et al., 1995). Adenosine and ATP receptors are widely distributed (Burnstock, 1990; Salter et al., 1993) and are present on several types of glial cells such as cultured astrocytes (Lai and Wong, 1991; Salter and Hicks, 1994), glioma cells (Chueh et al., 1994), microglial cells (Walz et al., 1993), and glial cells of the rat optic nerve (Kriegler and Chiu, 1993). Moreover, ATP appears necessary for the spread of $\mathrm{Ca}^{2+}$ waves in a syncytium of astrocytes (Guthrie et al., 1999).

The results of the present study suggest that PSCs possess adenosine receptors of A1 type, as indicated by the blockade of adenosine-induced $\mathrm{Ca}^{2+}$ responses by $\mathrm{CPT}$, an A1 receptor antagonist. However, and somewhat unexpectedly, $\mathrm{Ca}^{2+}$ responses induced by local applications of ATP were not blocked by suramin, a nonspecific $\mathrm{P} 2$ receptor antagonist indicating that the effects observed with ATP were not attributable to the activation of $\mathrm{P} 2$ receptors. In addition, adenosine released during synaptic activity triggers $\mathrm{Ca}^{2+}$ responses, as indicated by the significant reduction of $\mathrm{Ca}^{2+}$ responses elicited by nerve stimulation in the presence of CPT. However, at the amphibian NMJ, ATP released during synaptic transmission activates PSCs, whereas endogenous adenosine had no apparent effect on nerve-evoked $\mathrm{Ca}^{2+}$ responses (Robitaille, 1995).

Because of the presence of ecto-ATPases (Zimmermann, 1994), one possibility might have been that ATP-induced responses were caused by the indirect activation of adenosine receptors as a consequence of ATP degradation into adenosine. However, our results are not consistent with this possibility because ATP-induced $\mathrm{Ca}^{2+}$ responses persisted even in the presence of the adenosine receptor antagonist. An alternative possibility might be that ATP acted via ectoprotein-kinases because they are known to be located on the surface of several cells (Zimmermann, 1994) and that they require the presence of $\mathrm{Mg}^{2+}$ ions (Ehrlich et al., 1986), conditions in which our experiments were performed.

\section{Glial cells detect neuronal activity and synaptic transmission}

Glial cells at CNS synapses detect the release of neurotransmitters induced by neuronal activity (Porter and McCarthy, 1996, 1997; Carmignoto et al., 1998; Grosche et al., 1999). This does not require the activation of a complex multicellular network because similar results were obtained at the frog NMJ where PSCs detect and are modulated by synaptic activity generated by a single synapse (Jahromi et al., 1992; Georgiou et al., 1994, 1999; Robitaille, 1995; Robitaille et al., 1997; Bourque and Robitaille, 1998).

The data presented here demonstrate that mammalian PSCs can also detect synaptic activity and that a number of $\mathrm{Ca}^{2+}$ dependent cascades of events are likely triggered in PSCs as a consequence of the $\mathrm{Ca}^{2+}$ elevations. This observation is consistent with the properties reported for all other synapses at which synapse-glia interactions have been studied (Araque et al., 1999; Castonguay et al., 2001). Indeed, synaptic activity will trigger an elevation of intracellular $\mathrm{Ca}^{2+}$ in PSCs as a result of its release from internal stores. Moreover, this activation is frequency dependent and is regulated by the main neurotransmitters present at the synapse, regulating G-protein-coupled receptors. Hence, the results obtained at the mouse NMJ further support the concept that synapse-glia interactions are ubiquitous at chemical synapses where glial processes are present.

Because synapse-glia interactions are dependent on the release of neurotransmitters by chemical synapses (Araque et al., 1999; Castonguay et al., 2001), it is expected that the activity of perisynaptic glial cells will be governed by the main neurotransmitters found at the synapses with which they are associated. In the present study, it is shown that PSCs activation requires the release of neurotransmitter, as shown by the blockade of transmitter release with $\omega$-CgTx MVIIC. In particular, ACh released during synaptic transmission modulates the activity of the PSCs because $\mathrm{Ca}^{2+}$ responses were almost completely abolished in the presence of the muscarinic receptor antagonist atropine. Consistent with this observation and similar to $\mathrm{ACh}$-induced $\mathrm{Ca}^{2+}$ responses, we found that $\mathrm{Ca}^{2+}$ responses induced by evoked transmitter release also showed a pronounced rundown when elicited by repetitive trains of stimuli. This property was also present at PSCs of the amphibian NMJ (Jahromi et al., 1992) where a large part of this rundown was shown to be caused by endogenously released substance $\mathrm{P}$ that activates NK-1 receptors leading to reduced efficacy of purinergic and muscarinic receptor systems (Bourque and Robitaille, 1998).

\section{Functional differences of mammalian and amphibian PSCs}

Although mammalian and amphibian PSCs share a number of properties, there are a few major functional differences (Table 1). First, the type of receptors present are different. Indeed, PSCs of the amphibian NMJ lack sensitivity to general muscarinic antagonists, in particular to atropine, whereas we showed in this study that mammalian PSCs were atropine-sensitive. Also, the purinergic receptors are different because, unlike mouse PSCs, there is evidence in amphibian PSCs of two ATP receptor subtypes $\left(\mathrm{P}_{2 \mathrm{X}}\right.$, $\mathrm{P}_{2 \mathrm{Y}}$ ) in addition to A1 receptors (Robitaille, 1995). The second major difference resides in the molecular machinery associated with the receptors. Indeed, repetitive $\mathrm{Ca}^{2+}$ elevations were observed in mammalian PSCs after single applications of muscarine 
or stimulation of the motor nerve. This was not observed at amphibian PSCs where muscarine induced a single, large increase in $\mathrm{Ca}^{2+}$ (Jahromi et al., 1992; Robitaille, 1995; Robitaille et al., 1997). Moreover, the $\mathrm{Ca}^{2+}$ responses appear negatively regulated by external $\mathrm{Ca}^{2+}$ at mammalian but not at amphibian PSCs. The presence of the negative regulation by external $\mathrm{Ca}^{2+}$ are consistent with a calcium-dependent/calcium-release phenomenon that would only be present in mammalian PSCs. This negative $\mathrm{Ca}^{2+}$ regulation may contribute to the genesis of the repeated $\mathrm{Ca}^{2+}$ elevations observed in PSCs and to the more pronounced rundown of consecutive $\mathrm{Ca}^{2+}$ responses elicited at mammalian PSCs. These differences will have major impacts on the functions of PSCs because different types of receptors will have different regulatory actions resulting the production of different second messengers. Also, the different $\mathrm{Ca}^{2+}$ regulation in PSCs will result in the induction of different $\mathrm{Ca}^{2+}$-dependent mechanisms. Hence, although amphibian and mammalian NMJs show fundamental synapse-glia interactions, the properties of these interactions differ.

\section{Properties of synapse-glia interactions as a function of synapse identity}

Based on our data, we propose that, although synapse-glia interaction is a common phenomenon at chemical synapses associated with glial cells, the nature and the extend of the interactions will be fine-tuned according to the properties and function of the synapse with which they are associated. Because perisynaptic glial cells are involved in the modulation of synaptic transmission (Parpura et al., 1994; Robitaille, 1998; Araque et al., 1999; Castonguay et al., 2001), their involvement in the regulation of synaptic functions will be tuned according to their functional properties and, hence, adjusted to their synaptic environment. This adaptation to the synaptic environment is essential for perisynaptic glial cells to actively and effectively modulate synaptic efficacy and neuronal activity. Thus, it will be critical to establish the properties of the regulation of synaptic efficacy by PSCs at the mouse NMJ and determine how the different properties of PSCs at this synapse will influence their regulation of synaptic activity. Moreover, because of the importance of PSCs in the regulation of numerous crucial aspects of the synapse, a malfunction of Schwann cells (Scherer, 1997) will undoubtedly impair its functions.

\section{REFERENCES}

Araque A, Parpura V, Sanzgiri RP, Haydon PG (1999) Tripartite synapses: glia, the unacknowledged partner. Trends Neurosci 22:208-215.

Barres BA, Chun LL, Corey DP (1990) Ion channels in vertebrate glia. Annu Rev Neurosci 13:441-474.

Benham CD (1989) ATP activated channels gate calcium entry in single smooth muscle cells dissociated from rabbit ear artery. J Physiol (Lond) 419:689-701.

Bezzi P, Carmignoto G, Pasti L, Vesce S, Rossi D, Rizzini BL, Pozzan T, Volterra A (1998) Prostaglandins stimulate calcium-dependent glutamate release in astrocytes. Nature 391:281-285.

Bourque M-J, Robitaille R (1998) Endogenous peptidergic modulation of perisynaptic Schwann cells at the frog neuromuscular junction. J Physiol (Lond) 512:197-209.

Burnstock G (1990) Purinergic mechanisms. Ann NY Acad Sci 603:1-17.

Carmignoto G, Pasti L, Pozzan T (1998) On the role of voltagedependent calcium channels in calcium signaling of astrocytes in situ. J Neurosci 18:4637-4645.

Castonguay A, Robitaille R (2001) Differential regulation of transmitter release by presynaptic and glial internal stores at the neuromuscular synapse. J Neurosci 21:1911-1922.

Castonguay A, Lévesque L, Robitaille R (2001) Glial cells as active partners in synaptic function. Prog Brain Res, in press.

Chueh S-H, Hsu L-S, Song S (1994) Two distinct ATP signaling mech- anisms in differentiated neuroblastoma X glioma hybrid NG108-15 cells. Mol Pharmacol 45:532-539.

Dave V, Gordon GW, McCarthy KD (1991) Cerebral type 2 astroglia are heterogenous with respect to their ability to respond to neuroligands linked to calcium mobilization. Glia 4:440-447.

Ehrlich YH, Davis TB, Bock E, Kornecki E, Lenox R (1986) Ectoprotein kinase activity on the external surface of neural cells. Nature 320:67-70.

Georgiou J, Robitaille R, Trimble WS, Charlton MP (1994) Synaptic regulation of glial protein expression in vivo. Neuron 12:443-455.

Georgiou J, Robitaille R, Charlton MP (1999) Muscarinic control of cytoskeleton in perisynaptic glia. J Neurosci 19:3836-3846.

Grosche J, Matyash V, Moller T, Verkhratsky A, Reichenbach A, Kettenmann H (1999) Microdomain for neuron-glia interaction: parallel fiber signaling to Bergmann glial cells. Nat Neurosci 2:139-143.

Guthrie PB, Knappenberger J, Segal M, Bennett MVL, Charles AC, Kater SB (1999) ATP released from astrocytes mediates glial calcium waves. J Neurosci 19:520-528.

Hamprecht B (1986) Astroglia cells in culture: receptors and cyclic nucleotides. In: Astrocytes (Fedoroff S., Vernadakis A., eds), pp 261-294. Orlando, FL: Academic.

Herrera AA, Qiang H, Ko C-P (2000) The role of perisynaptic Schwann cells in development of neuromuscular junctions in the frog (Xenopus leavis). J Neurobiol 45:237-254.

Jahromi BS, Robitaille R, Charlton MP (1992) Transmitter release increases intracellular calcium in perisynaptic Schwann cells in situ. Neuron 8:1069-1077.

Katz E, Protti DA, Ferro PA, Rosato Siri MD, Uchitel OD (1996) Effects of $\mathrm{Ca}^{2+}$ channel blockers on transmitter release and presynaptic currents at the mouse neuromuscular junction. $\mathrm{Br} \mathrm{J}$ Pharmacol 121:1531-1540.

Koirala S, Qiang H, Ko C-P (2000) Reciprocal interactions between perisynaptic Schwann cells and regenerating nerve terminals at the frog neuromuscular junction. J Neurobiol 44:343-360.

Kriegler S, Chiu SY (1993) Calcium signaling of glial cells along mammalian axons. J Neurosci 13:4229-4245.

Lai K-M, Wong PCL (1991) Metabolism of extracellular adenine nucleotides by cultured rat brain astrocytes. J Neurochem 57:1510-1515.

Lyons SA, Morell P, McCarthy KD (1995) Schwann cell ATP-mediated calcium increases in vitro and in situ are dependent on contact with neurons. Glia 13:27-38.

MacVicar BA (1984) Voltage-dependent calcium channels in glial cells. Science 226:1345-1347.

Nedergaard M (1994) Direct signaling from astrocytes to neurons in cultures of mammalian brain cells. Science 263:1768-1771.

Newman EA (1986) Regional specialization of the membrane of retinal glial cells and its importance to $\mathrm{K}^{+}$spatial buffering. Ann NY Acad Sci 481:273-286.

Newman EA, Zahs KR (1998) Modulation of neuronal activity by glial cells in the retina. J Neurosci 18:4022-4028.

Parpura V, Basarsky TA, Liu F, Jeftinija K, Jeftinija S, Haydon PG (1994) Glutamate-mediated astrocyte-neuron signalling. Nature 369:744-747.

Pfrieger FW, Barres BA (1997) Synaptic efficacy enhanced by glial cells in vitro. Science 277:1684-1687.

Porter JT, McCarthy KD (1996) Hippocampal astrocytes in situ respond to glutamate released from synaptic terminals. $\mathrm{J}$ Neurosci 16:5073-5081.

Porter JT, McCarthy KD (1997) Astrocytic neurotransmitter receptors in situ and in vivo. Prog Neurobiol 51:439-455.

Reist NE, Smith SJ (1992) Neurally evoked calcium transients in terminal Schwann cells at the neuromuscular junction. Proc Natl Acad Sci USA 89:7625-7629.

Robitaille R (1995) Purinergic receptors and their activation by endogenous purines at perisynaptic glial cells of the frog neuromuscular junction. J Neurosci 15:7121-7131.

Robitaille R (1998) Modulation of synaptic efficacy and synaptic depression by glial cells at the frog neuromuscular junction. Neuron 21:847-855.

Robitaille R, Bourque MJ, Vandaele S (1996) Localization of L-type $\mathrm{Ca}^{2+}$ channels at perisynaptic glial cells of the frog neuromuscular junction. J Neurosci 16:148-158.

Robitaille R, Jahromi BS, Charlton MP (1997) Muscarinic Ca ${ }^{2+}$ responses resistant to muscarinic antagonists at perisynaptic Schwann cells of the frog neuromuscular junction. J Physiol (Lond) 504: 337-347.

Salpeter MM (1987) The vertebrate neuromuscular junction, (Salpeter MM, ed). New York: Liss.

Salter MW, Hicks JL (1994) ATP-evoked increases in intracellular calcium in neurons and glia from the dorsal spinal cord. J Neurosci 14:1563-1575.

Salter MW, De Koninck Y, Henry JL (1993) Physiological roles for adenosine and ATP in synaptic transmission in the spinal dorsal horn. Prog Neurobiol 41:125-156. 
Scherer SS (1997) The biology and pathobiology of Schwann cells. Curr Opin Neurol 10:386-397.

Silinsky EM (1975) On the association between transmitter secretion and the release of adenine nucleotides from mammalian motor nerve terminals. J Physiol (Lond) 247:145-162.

Smith DO (1991) Sources of adenosine released during neuromuscular transmission in the rat. J Physiol (Lond) 432:343-354.

Sneddon P, Burnstock G (1984) ATP as a cotransmitter in rat tail artery. Eur J Pharmacol 106:149-152.

Son Y-J, Thompson WJ (1995a) Schwann cell processes guide regeneration of peripheral axons. Neuron 14:125-132.

Son Y-J, Thompson WJ (1995b) Nerve sprouting in muscle is induced and guided by processes extended by Schwann cells. Neuron 14:133-141.

Son Y-J, Trachtenberg JT, Thompson WJ (1996) Schwann cells induce and guide sprouting and reinnervation of neuromuscular junctions. Trends Neurosci 19:280-285.

Tsien RY (1989) Fluorescent probes of cell signaling. Annu Rev Neurosci 12:227-253.

Walz W, Ilschner S, Ohlemeyer C, Banati R, Kettenmann H (1993) Extracellular ATP activates a cation conductance and a $\mathrm{K}^{+}$conductance in cultured microglial cells from mouse brain. J Neurosci 13: $4403-4411$

Ziganshin AU, Hoyle CH, Bo X, Lambrecht G, Mutschler E, Baumert HG, Burnstock G (1993) PPADS selectively antagonizes P2Xpurinoceptor-mediated responses in the rabbit urinary bladder. $\mathrm{Br} \mathrm{J}$ Pharmacol 110:1491-1495.

Zimmermann H (1994) Signalling via ATP in the nervous system. Trends Neurosci 17:420-426. 